\title{
Impacts of regional climate change on barley yield and its geographical variation in South Korea**
}

\author{
Jonghan $\mathrm{Ko}^{1 *}$, Chi Tim $\mathrm{Ng}^{2 *}$, Seungtaek Jeong ${ }^{1}$, Jun-Hwan Kim ${ }^{3}$, Byunwoo Lee ${ }^{4}$, and Han-Yong Kim ${ }^{1}$ \\ ${ }^{1}$ Applied Plant Science, Chonnam National University, 77 Yongbong-ro, Buk-gu, Gwangju 61186, Republic of Korea \\ ${ }^{2}$ Statistics, Chonnam National University, 77 Yongbong-ro, Buk-gu, Gwangju 61186, Republic of Korea \\ ${ }^{3}$ Crop Production and Physiology Research, National Institute of Crop Science, 181 Hyeoksin-ro, Iseo-myeon, Wanju-Gun, \\ Jeollabuk-do 55365, Republic of Korea \\ ${ }^{4}$ Department of Plant Science, Seoul National University, 1 Gwanak-ro, Gwanak-gu, Seoul 08826, Republic of Korea
}

Received May 20, 2018; accepted November 13, 2018

\begin{abstract}
Geospatial variations in barley production due to climate change were evaluated for different geographic regions of South Korea over the next hundred years under the climate change scenarios of representative concentration pathways 4.5 and 8.5. We employed a geospatial crop simulation modelling strategy based on the CERES-barley model in the DSSAT crop model package version 4.6 to simulate grid-based geospatial variation in barley yield. An open field experiment and a temperature gradient field chamber experiment were performed to obtain model coefficients for South Korea and to assess the performance of CERES-barley under elevated temperature conditions. Projected barley yield data were further used to establish a new landscape classification system to provide agricultural policymakers with useful information on coping with climate change. Expected yields of four barley cultivars for the whole nation showed moderate increases under representative concentration pathways 4.5 and rapid increases under representative concentration pathways 8.5. More differences in yield were observed between different geospatial regions. Based on k-means clustering and the impact of climate change on barley yield, regional characteristics of the whole country could be classified into six categories. The geospatial crop simulation modelling could be extended to determine geospatial variations in staple crop productions due to other environmental scenarios of interest.
\end{abstract}

Keyw ords: barley, climate change, crop model, geospatial projection, yield

*Corresponding authors e-mail: jonghan.ko@jnu.ac.kr, easterlyng@gmail.com

**This study was financially supported by Chonnam National University (Grant number: 2016-2651). Chi Tim Ng's research was supported by a National Research Foundation of Korea (NRF) grant (NRF-2017R1C1B2011652) funded by the Korean government (MSIP).

\section{INTRODUCTION}

Global carbon dioxide $\left(\mathrm{CO}_{2}\right)$ concentration will likely increase to a range of 421 to $936 \mathrm{ppm}$, associated with an increase in mean global surface temperature between 2000 and 2100 (IPCC, 2013). The Intergovernmental Panel on Climate Change (IPCC) has projected that the global warming trend from 1986-2005 to 2081-2100 will show a temperature increase of $0.3^{\circ} \mathrm{C}$ to $1.7^{\circ} \mathrm{C}$ based on representative concentration pathways 2.6 (RCP), 1.1 to $2.6^{\circ} \mathrm{C}$ based on RCP $4.5,1.4^{\circ} \mathrm{C}$ to $3.1^{\circ} \mathrm{C}$ based on RCP6.0, and 2.6 to $4.8^{\circ} \mathrm{C}$ based on RCP8.5. Elevation of atmospheric $\mathrm{CO}_{2}$ concentration and the accompanying increase in temperature is expected to affect agricultural production due to changes in evapotranspiration, plant growth rates, plant litter composition, and the nitrogen-carbon cycle (Long et al., 2006). Consequences in a particular location are likely to vary depending on the magnitude of these changes, responses of specific crops, location-specific management, and socio-economic conditions. It is essential to investigate the regional impact of projected increases in anthropogenic greenhouse gases (GHGs) and subsequent global climate change on the production of crops of interest to understand the effect of climate change on local crop production of interest and recommend appropriate adaptation measures in time.

(C) 2019 Institute of Agrophysics, Polish Academy of Sciences 
Among many crops of international interest, barley (Hordeum vulgare) is one of the primary cereal crops. Barley is grown on every continent on which crops are grown because it can adapt to various environmental conditions. Thus, it is produced with a wider topographical distribution than most other cereals. World barley production in 2014 was 144 million $t$, ranking the fourth in grain production (FAO, 2017). In South Korea, barley can be cultivated in all provinces, ranging from Jeju Island in the south to Kangwon in the north, covering a total of six different climate categories (Cfa, Cwa, Dfa, Dfb, Dwa, and Dwb) under the Koeppen-Geiger climate classification system (Kottek et al., 2006). Under this grouping system, small letters $a$ and $b$ refer to hot and warm summer, respectively, while $w$ and $\mathrm{f}$ refer to dry winter and fully humid, respectively. This country encompasses coastal and inner continental regions that respond differently to climate change. Given the variable climate and soil conditions, both policymakers and agriculturalists need more sophisticated systems to access regional variances in the influence of climate change on crop production.

Crop growth and development depend on integrated responses of various eco-physiological processes considering multiple environmental conditions such as temperature, $\mathrm{CO}_{2}$ concentration, nutrients, water, and field management. Not even an enormous effort would guarantee the elucidation of these variables and their interactions in a field experiment examining potential effects on agricultural production. Therefore, it is crucial to develop agricultural system models that are calibrated efficiently and validated to investigate the combined effect of various chemical, physical, and biological processes (Ahuja et al., 2000; Kirschbaum, 2000; Zawadzki et al., 2005). Process-based crop models that simulate the development process of biomass and yield components are valued evaluating the impact of climate change on crop growth and development. Crop models frequently used to simulate the growth and development of barley include CERES-barley (Otter-Nacke et al., 1991) in the Decision Support System for Agrotechnology Transfer (DSSAT) (Jones et al., 2003), environmental policy integrated climate (EPIC) model (Williams et al., 1998), SHOOTGROW (McMaster, 1993), and World Food Studies (WOFOST) model (Hijmans et al., 1994).

Many studies have examined the physiology and productivity of barley under climate change (Bunce, 2000; Chloupeka et al., 2004; Trnka et al., 2004; Tubiello et al., 2000; Olesen et al., 2011; Tao et al., 2017). Some of these efforts were made based on experimental field studies while others used crop simulation approaches. Bunce (2000) reported the effect of temperature and $\mathrm{CO}_{2}$ changes under subjectively designed experimental conditions. Trnka et al. (2004) used crop simulation to examine future temperature using chronological models based on assumptions that autoregressive parameters and $\mathrm{CO}_{2}$ level would remain constant. Tao et al. (2017) have recently reported an approach to design future barley ideotypes using a crop model ensemble. Similarly to these efforts, it would add more realistic values to crop simulation if the applied projected temperature regimes and $\mathrm{CO}_{2}$ concentrations were based on more realistic physical models. In this research, we considered $\mathrm{CO}_{2}$ level under different $\mathrm{RCP}$ scenarios and the expected temperature provided by the Korea Meteorological Administration (KMA). These data were compiled based on two coupled climate models: the Hadley Centre Global Environmental Model version 2-Atmosphere-Ocean (HadGEM2-AO) model and the Hadley Centre Global Environmental Model version 3-Regional Atmosphere (HadGEM3-RA) model.

The objective of the present research was to project geospatial variation in barley yield for different geographic regions of South Korea due to climate change for the next 100 years. Based on the sensitivities to climate change, clustering analysis was achieved to categorise South Korea into different topographical regions. Simulation studies were performed to achieve the research objective following estimation and evaluation of the six coefficients of the CERES-barley model for four barley cultivars commonly grown in South Korea. We also developed a geospatial crop simulation modelling (GCSM) scheme to project the geographical variation in production of barley under climate change and to seek for future adaptation measures using the developed simulation design.

\section{MATERIALS AND METHODS}

This research was performed using the CERES-barley model in the DSSAT crop model package v4.6. Field experiments were conducted at Chonnam National University (CNU; $35^{\circ} 10^{\prime} \mathrm{N}, 126^{\circ} 53^{\prime} \mathrm{E}, 33 \mathrm{~m}$ above sea level), Gwangju (Fig. 1a). An open field experiment was performed to collect data to estimate six genetic coefficients of CERES-barley. A TGFC experiment was carried out to test the performance of the estimated model at elevated temperatures. The country including all its islands lies between latitudes of $33^{\circ}$ and $39^{\circ} \mathrm{N}$ and longitudes of $124^{\circ}$ and $131^{\circ} \mathrm{E}$. It has a total area of $\sim 100032 \mathrm{~km}^{2}$. The 30-year average annual temperatures in regions of interest where barley could be cultivated ranged from $\sim 10$ to $15^{\circ} \mathrm{C}$ according to the Korea Meteorological Administration, KMA (https://data.kma. go.kr/). The corresponding average annual total precipitation amounts varied from $\sim 1000$ to $1800 \mathrm{~mm}$, of which $\sim 60 \%$ of the rainfall was concentrated between June and September.

The open field experiment was carried out from 2013 to 2016 for three barley-growing seasons at CNU to determine genetic coefficients of four winter barley varieties (Hordeum vulgare L. var. nudum Hook. f. cv. SaeChal, HeenChal, KeunAl, and Dajin). Among cultivars bred by the National Institute of Crop Science (http://www.nics. go.kr/english/index.do), we deliberately chose two naked 
(a)
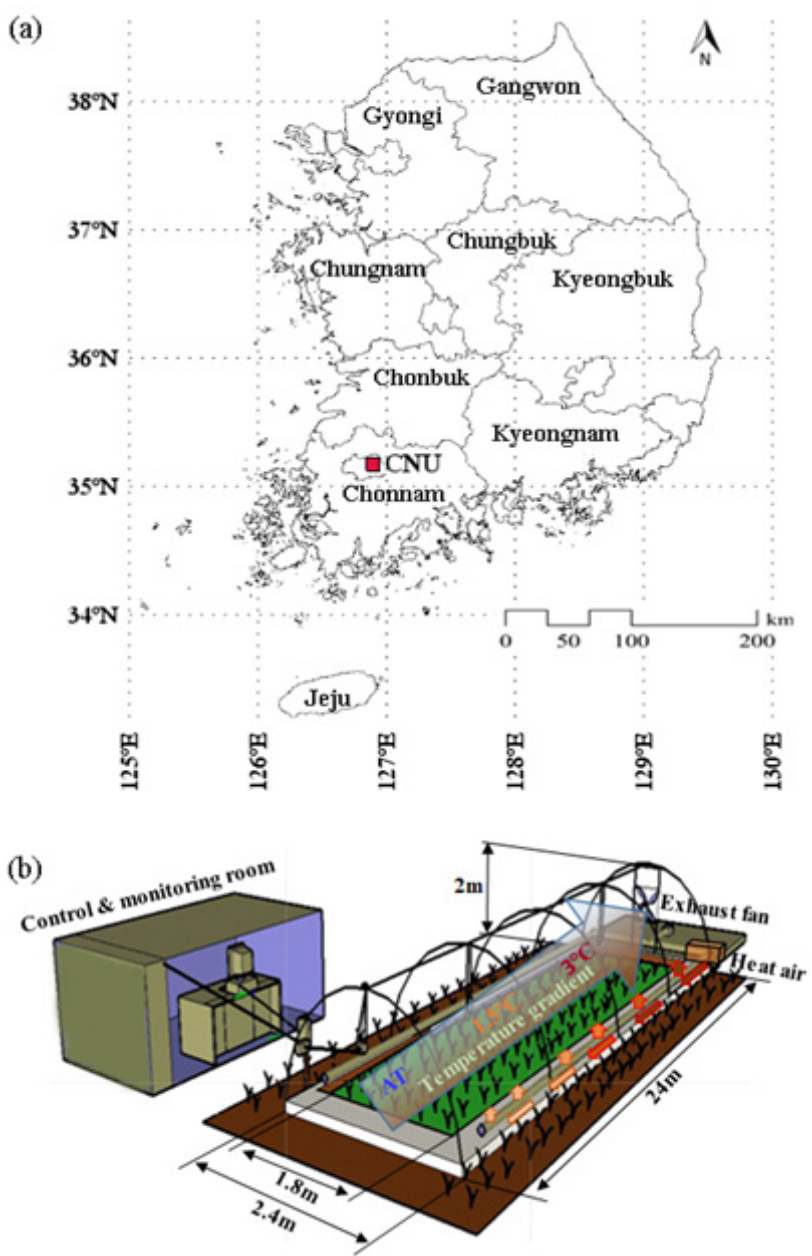

Fig. 1. Map of the research site at Chonnam National University (CNU), Gwangju and nine provinces in South Korea (a) and schematic illustration of the temperature gradient field chamber (b).

cultivars of SaeChal (bred in 1994) and HeenChal (bred in 1993) and two hooded cultivars of KeunAl (bred in 1993) and Dajin (bred in 2005 as a malting cultivar). These barley varieties were seeded at a planting rate of $140 \mathrm{~kg} \mathrm{ha}^{-1}$ on 6 November 2013 (day of year, DOY 310), 10 November 2014 (DOY 314), and 5 November 2015 (DOY 309) in a field arranged as three randomised complete blocks. Soil texture of the experimental area was categorised as loam (Fluvisol with total organic carbon $12.3 \mathrm{~g} \mathrm{~kg}^{-1}$, total nitrogen $1.0 \mathrm{~g} \mathrm{~kg}^{-1}$, available phosphate $13.1 \mathrm{~g} \mathrm{~kg}^{-1}$, and soil $\mathrm{pH}$ in $\mathrm{H}_{2} \mathrm{O}$ of 5.5), based on the United States Department of Agriculture (USDA) classification method (for specific soil properties, refer to Yun et al., 2012). The field was managed with optimum $\mathrm{N}-\mathrm{P}_{2} \mathrm{O}_{5}-\mathrm{K}_{2} \mathrm{O}$ fertilisation of 80-70$35 \mathrm{~kg} \mathrm{ha}^{-1}$ in three crop seasons. Total yield was estimated by multiplying yield components.

To measure yield components including ears per $\mathrm{m}^{2}$, spikelets per ear, the percentage of filled grain (PFG), and 1000 -grain weight $(\mathrm{GW})$, ten plants were randomly pruned from middle rows of each plot before harvest. PFG was determined by dividing the total number of grains by the number of grain-filling seed as a measure of filled grains. The 1000-GW was used to represent the weight of a single grain because the latter was very small. Grain-filling seed was used to determine the $1000-\mathrm{GW}$. These components of yield were measured three times in each experimental plot. Weather data were measured using an automated weather station (WS-GP1, Delta-T Devices, Cambridge, UK).

The CERES-barley was calibrated using data obtained from the TGFC system (Fig. 1b) located at CNU for two barley-growing seasons from 2014 to 2016. The TGFC used in this study (Kim et al., 2011) was designed to mimic projected shifts in atmospheric air temperature based on RCP scenario of climate change (IPCC, 2013). Two different barley cultivars (SaeChal and HeenChal) were sown at a seeding rate of $140 \mathrm{~kg} \mathrm{ha}^{-1}$ on 3 November 2014 (DOY 307) and 2 November 2015 (DOY 306) in TGFCs laid out as three randomised complete blocks. Primary TGFC treatments included three temperature levels: local ambient temperature (AT), $1.5^{\circ} \mathrm{C}$ above $\mathrm{AT}$, and $3.0^{\circ} \mathrm{C}$ above AT. These three temperature levels were assigned as main plots with two cultivar treatments, encompassing six experimental conditions. Fertilisation and yield estimation were the same as those described earlier in the open field experiment except that components of yield were measured one time in each plot due to limited plant population in the TGFCs. Plant data from 2014-2015 in the TGFC experiment were used to calibrate the model while those data from 20152016 were used to validate the model.

Environmental data applied to simulate the impact of climate change on barley yield in this study included: (1) soil data, (2) projected climate data, and (3) projected $\mathrm{CO}_{2}$ concentration data. Pixel-based soil data were obtained from digital soil maps (1:5000) for the entire country from the National Academy of Agricultural Science (NAAS), South Korea (http://soil.rda.go.kr/eng/). Please refer to Hong et al. (2009) for a detailed soil inventory. Based on these soil data, information about topsoil properties, soil type, effective soil depth, and soil structure for the corresponding region was aggregated to determine soil input parameters of the CERES-barley model in the GCSM system. Based on the aggregated soil information, the GCSM system empirically selected one of the eight potential soil input libraries predetermined for barley cultivation in South Korea using the generic soil input inventory of the DSSAT crop model package v4.6 (Table 1). Climate data from 12 years (1999-2011) with a 3-km grid cell resolution for South Korea were used as baseline climate data for the model input in the GCSM system. These climate data were projected using a regional climate model (Weather Research and Forecasting Model, WRF) based on a dynamical downscaling method to obtain high-resolution regional agro-climate indices (Ahn et al., 2010). 
Table 1. Soil information used in this study

\begin{tabular}{llccc}
\hline \multirow{2}{*}{ ID } & Texture & Depth $(\mathrm{cm})$ & \multicolumn{2}{c}{ Soil water* $\left(\mathrm{cm}^{3} \mathrm{~cm}^{-3}\right)$} \\
\cline { 3 - 4 } IB00000002 & Medium silty clay & 150 & CLL & 0.228 \\
IB00000003 & Shallow silty clay & 60 & 0.228 & 0.385 \\
IB00000005 & Medium silty loam & 150 & 0.108 & 0.218 \\
IB00000006 & Shallow silty loam & 60 & 0.108 & 0.218 \\
IB00000008 & Medium sandy loam & 150 & 0.052 & 0.176 \\
IB00000009 & Shallow sandy loam & 60 & 0.052 & 0.176 \\
IB00000011 & Medium sand & 150 & 0.024 & 0.096 \\
IB00000012 & Shallow sand & 60 & 0.024 & 0.096 \\
\hline
\end{tabular}

*Volumetric water content of the topsoil averaged among 5, 15, and $30 \mathrm{~cm}$ at the crop lower limit (CLL) and at the drained upper limit (DUL), respectively.

Climate change scenarios were obtained from Coordinated Regional climate Downscaling Experiment (CORDEX) initiative created by the Task Force for Regional Climate Downscaling (TFRCD) and established by the World Climate Research Programme (WCRP) in 2009. Regional climate model HadGEM3-RA and general circulation model HadGEM2-AO were used to simulate regional climate change projections in South Korea under two emission scenarios related to RCP4.5 and RCP8.5 (IPCC, 2013). Large-scale climate variables from HadGEM2-AO were dynamically downscaled to a physically consistent evolution on a smaller $(0.44 \times 0.44$ degree $)$ scale using the HadGEM3-RA model. Further information on these models can be found at the CORDEX-East Asia website (http:// cordex-ea.climate.go.kr/). Projected changes in temperature and precipitation in South Korea under RCP4.5 and RCP8.5 associated with $\mathrm{CO}_{2}$ concentration were simulated for future years centred on 2030, 2050, 2070, and 2100 . Regional shifts estimated from baseline regional climate data were incorporated into the primary trend of climate change to produce regional projections of daily climate data. These projected data were used for each 12-year projection based on the 12-year baseline (1999 to 2011), centered on 2005 , to include inter-annual climate variability. These projected variations in temperature and precipitation were superimposed on the 12-year baseline. This method was previously used for projection of daily climate change in the Central Great Plains, USA (Ko et al., 2012).

The CERES-barley model in the DSSAT crop model package v4.6 (www.DSSAT.net) is a process-based management-level model developed for simulations of grain yield, grain development, soil water, and soil nutrient balance associated with barley growth. Here, we highlighted the difference between our research and the common practice in using the CERES-barley model. In the CERES-barley model, climate, $\mathrm{CO}_{2}$ concentration, and soil data are independent variables. In our research, we noted that long-term global climate depended on $\mathrm{CO}_{2}$ concentration. Therefore, $\mathrm{CO}_{2}$ concentration can influence crop growth through tem- perature change and solar radiation use efficiency (RUE). These factors will be discussed in more details in the next subsection. The CERES-barley model calculates the net biomass production using the RUE approach. Effects of elevated $\mathrm{CO}_{2}$ concentration on RUE have been modelled empirically using curvilinear multipliers (Allen et al., 1987; Peart et al., 1989). A y-intercept term in a modified Michaelis-Menten equation is used to fit crop responses to various $\mathrm{CO}_{2}$ concentrations:

$$
R=\frac{R_{m} \mathrm{CO}_{2}}{\mathrm{CO}_{2}+K_{m}}+R_{i}
$$

where: $R$ is RUE, yield or other responses; $R_{m}$ is the asymptotic response limit of $\left(R-R_{i}\right)$ at a high $\mathrm{CO}_{2}$ concentration; $R_{i}$ is the intercept on the y-axis; and $K_{m}$ is the value of substrate concentration, that is, $\mathrm{CO}_{2}$, at which $\left(R-R_{i}\right)=0.5 R_{m}$. Similar approaches have been used to simulate the effect of $\mathrm{CO}_{2}$ on cropping systems in EPIC (Williams et al., 1989), agricultural production systems simulator (APSIM) along withnitrogenuseefficiencyandwateruseefficiency(Reyenga et al., 1999), and Sirius (Jamieson et al., 2000) models. The model accuracy was validated and applied to simulate the future impact of climate change in South Korea.

The minimum driving variables for model simulations were daily solar radiation, maximum and minimum temperatures, precipitation, physical and hydraulic properties of soil, soil texture, and initial soil nitrogen and soil water status. Typical crop management metadata included planting date, planting depth, row spacing plant population and amount and method of irrigation and fertiliser applications. To apply the CERES-barley model to project the impact of barley on climate change, six genetic coefficients $(\mathrm{P} 1 \mathrm{~V}$, G1, G3, P1V, G1, and G3) of four different varieties were parameterised. The model characterises the growth process of a barley species using these six genetic coefficients. An iterative approach recommended by Godwin et al. (1989) was employed to develop genetic coefficients based on trial and error to match the measured phenology and yields with simulated values. 


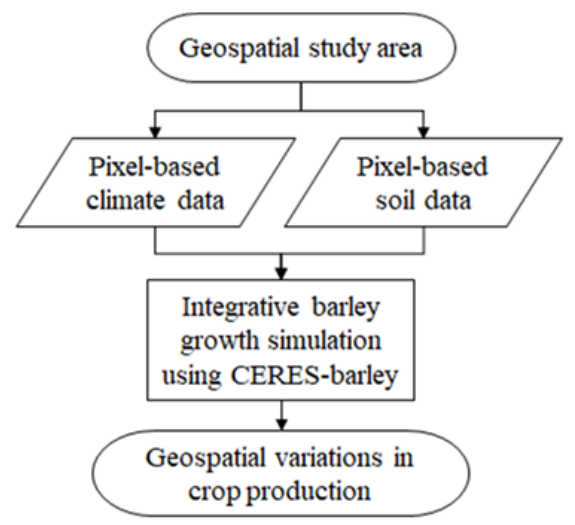

Fig. 2. Diagrammatic representation of the geospatial barley simulation design using the CERES-barley model.

The CERES-barley model was calibrated and validated using TGFC and open field experiment data obtained at CNU, Gwangju as described earlier. An initial test was then conducted to measure the sensitivity of the proposed model to changes in atmospheric $\mathrm{CO}_{2}$ concentration and temperature before it was applied to the whole geographical regions of South Korea. For this particular purpose, climate data collected over the past 12 years (1999-2011) were obtained from KMA and used as the standard upon which changes were superimposed to determine the inter-annual variability. The average value for each DOY was then calculated. $\mathrm{CO}_{2}$ concentrations ranging from 400 to $1000 \mu \mathrm{mol} \mathrm{mol}{ }^{-1}$ were used in $100 \mu \mathrm{mol} \mathrm{mol}^{-1}$ intervals. Temperature sensitivity was examined by varying measured daily maximum and minimum temperatures by 0 to $+10^{\circ} \mathrm{C}$ in $1^{\circ} \mathrm{C}$ intervals.

The GCSM scheme was formulated using CERESbarley in the DSSAT crop model package v4.6. In the GCSM scheme, the CERES-barley model was designed to perform numerous runs using pixel-based 2-dimensional climate and soil data based on shell scripting in a Linux operating system (Fig. 2). The GCSM strategy allows the whole country to be split into a 2-dimensional array of pixels, with each pixel representing an area of three kilometres by three kilometres. The pixel-by-pixel soil data provided by the NAAS and the projected climate data provided by the KMA were preprocessed and used as input for the CERES-barley model to generate pixel-by-pixel projected crop yield values over the next 100 years.

A statistical agreement evaluator used to assess the model performance of the simulation of yield was the p-value from a paired t-test. Also, two mathematical equations were used to analyse the model performance of the simulation: i) root mean square error (RMSE), Eq. (2); and ii) Nash-Sutcliffe model efficiency (NSME) (Nash and Sutcliffe 1970), Eq. (3).

$$
R M S E=\left[\frac{1}{N} \sum_{i=1}^{n}\left(S_{i}-M_{i}\right)^{2}\right]^{1 / 2}
$$

$$
N S M E=1-\frac{\sum_{i=1}^{n}\left(S_{i}-M_{i}\right)^{2}}{\sum_{i=1}^{n}\left(M_{i}-M_{\text {avg }}\right)^{2}}
$$

where: $S_{i}$ is the $i$ th simulated value, $M_{i}$ is the $i$ th measured value, $M_{a v g}$ is the mean measured value, and $n$ is the number of data pairs. NSME is a normalised statistic that defines the relative magnitude of the residual variance in comparison with observed data variance. NSME specifies how well the plot of observed compared to simulated data corresponds to the $1: 1$ line. NSME values vary from $-\infty$ to 1 . The nearer the value is to one, the more precise the model is. The lesser or closer to zero the value is, the lower (or equal) is the accurateness of the model prediction in comparison with the observed mean. Also, contributions of year, region, RCP scenario, cultivar, and their interactions were investigated according to the analysis of variance (ANOVA) using R software version 3.3 (https://www.r-project.org/).

To establish a landscape grouping system for South Korea, k-means clustering was applied to projected crop yield values. The entire country was categorised into topographical units according to crop production sensitivities about climate change. Eight variables were used: variations from the baseline to 2030, from 2030 to 2050, from 2050 to 2070 , and from 2070 to 2100 under both RCP4.5 and RCP8.5 scenarios. The k-mean clustering process was carried out using the "kmeans" function contained in the $\mathrm{R}$ software. This process was continued for each of the four species. In this study, $\mathrm{K}=6$ was selected. Although $\mathrm{K}>6$ could be deliberated, quantities of the new clusters were too small to be projected. All plots (Figs 8-10) were created using the R package "ggplot2".

In the $\mathrm{k}$-means clustering process, $\mathrm{K}$ first centres were randomly selected. Each pixel was categorised 1, 2, 3..., and $\mathrm{K}$ according to the Euclidean distance from these $\mathrm{K}$ centres. The average vector of each resulting cluster converted the new centre. These steps mentioned above were continued until convergence was reached, that is, both changes of means and labels from the old to further phase were adequately small to achieve a predefined stopping condition.

\section{RESULTS}

The mean solar radiation during the barley growing season was $12.1 \mathrm{MJ} \mathrm{m}^{-2} \mathrm{~d}^{-1}$ for 2013-2014, 10.1 $\mathrm{MJ} \mathrm{m}^{-2} \mathrm{~d}^{-1}$ for 2014-2015, and 12.4 $\mathrm{MJ} \mathrm{m}^{-2} \mathrm{~d}^{-1}$ for 2015-2016 (Fig. 3). Average temperature during the barley growing season was $7.9{ }^{\circ} \mathrm{C}$ for $2013-2014,7.7{ }^{\circ} \mathrm{C}$ for $2014-2015$, and $9.0{ }^{\circ} \mathrm{C}$ for 2015-2016. Cumulative mean growing season precipitation was $318.9 \mathrm{~mm}\left(1.8 \mathrm{~mm} \mathrm{~d}^{-1}\right)$ for 2013-2014, $462.9 \mathrm{~mm}$ $\left(2.2 \mathrm{~mm} \mathrm{~d}^{-1}\right)$ for $2014-2015$, and $363.4 \mathrm{~mm}\left(1.8 \mathrm{~mm} \mathrm{~d}^{-1}\right)$ for 2015-2016. The heaviest precipitation of the barley growing season was recorded on 24 November 2013 (DOY 186; $26.5 \mathrm{~mm} \mathrm{~d}^{-1}$ ), 24 November 2014 (DOY 328; $71.0 \mathrm{~mm} \mathrm{~d}^{-1}$ ), and 18 November 2015 (DOY 322; $34.5 \mathrm{~mm} \mathrm{~d}^{-1}$ ). 
a
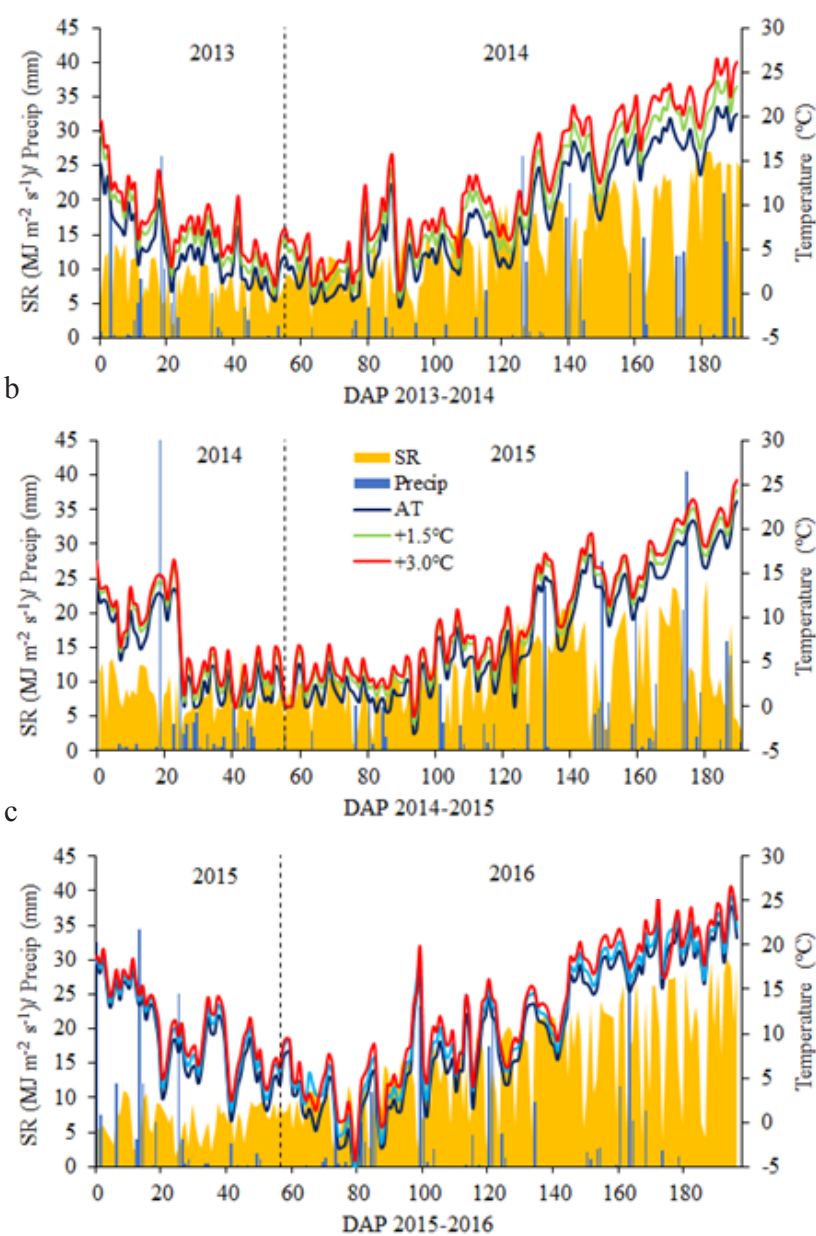

Fig. 3. Seasonal climate conditions during the barley growing seasons in 2013-2014 (a), 2014-2015 (b), and 2015-2016 (c). SR, solar radiation; Precip, precipitation; and AT represent solar radiation, precipitation, and atmospheric temperature, respectively.

A combination of cultivar parameters yielding minimum RMSE and maximum NSME values between measurements and simulations in growth and yield was selected during calibration of the CERES-barley model. In the calibration, CERES-barley reproduced well the growth and yield of the four barley cultivars grown in the field from 2014 to 2016 (Fig. 4a). Simulated mean grain yields of $4642 \mathrm{~kg} \mathrm{ha}^{-1}$ in $2014,4028 \mathrm{~kg} \mathrm{ha}^{-1}$ in 2015, and $4365 \mathrm{~kg} \mathrm{ha}^{-1}$ in 2016 were not significantly different from measured mean grain yields of $4388 \mathrm{~kg} \mathrm{ha}^{-1}$ in 2014 ( $\left.\mathrm{p}=0.591\right), 4,436 \mathrm{~kg} \mathrm{ha}^{-1}$ in 2015 ( $p=0.496)$, and $3308 \mathrm{~kg} \mathrm{ha}^{-1}$ in $2016(p=0.063)$ based on paired t-test. and NSME values were $697.1 \mathrm{~kg} \mathrm{ha}^{-1}$ and -5.60 in $2014,670.9 \mathrm{~kg} \mathrm{ha}^{-1}$ and -0.15 in 2015 , and $1217.0 \mathrm{~kg} \mathrm{ha}^{-1}$ and -126.30 in 2016, respectively. While estimated values of P1V, G1, and G3 were equivalent among these four cultivars, those of P1D, P5, G2, and PHINT varied (Table 2). Genetic parameters determined here were used for further evaluation and application processes of the model.
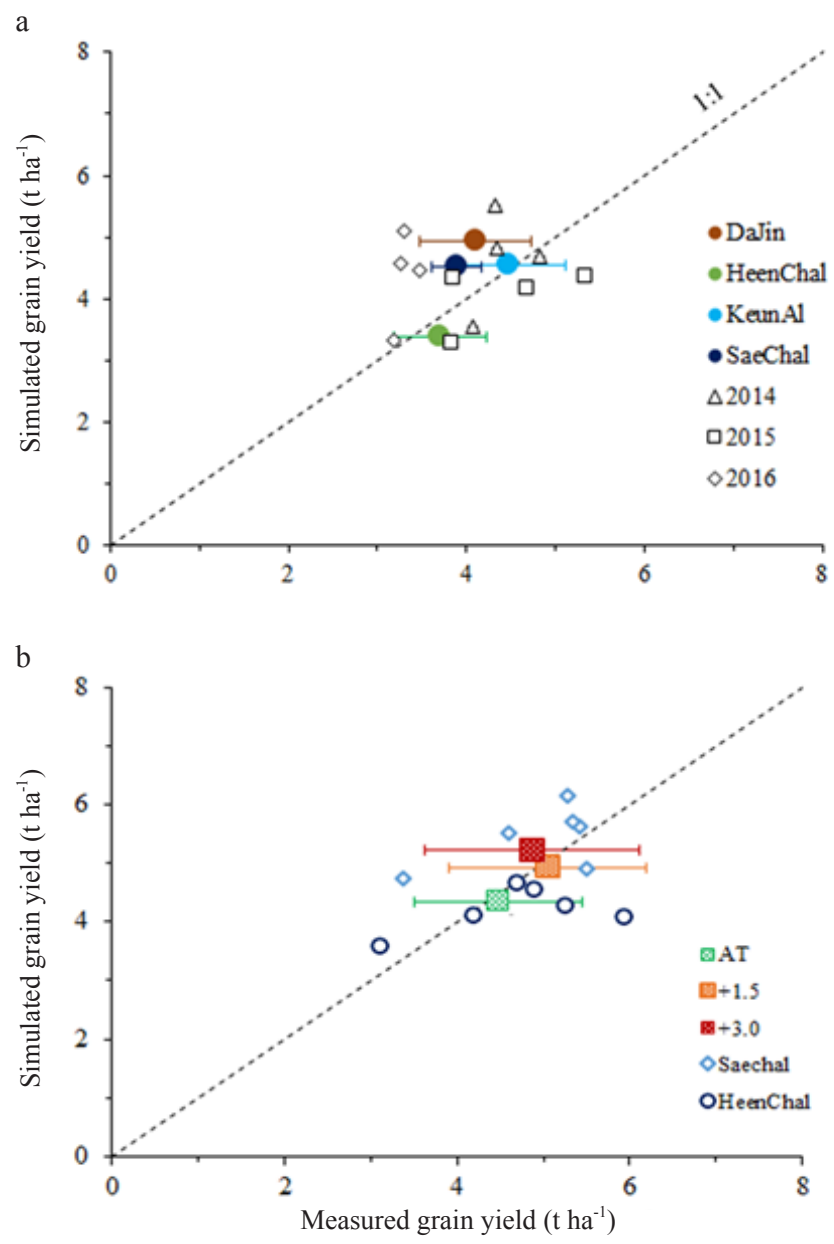

Fig. 4. Simulated vs. measured grain yields of barley for four local varieties of SaeChal, HeenChal, KeunAl, and Dajin during three crop seasons from 2014 to 2016 (a) and for three temperature regimes of atmospheric temperature (AT), +1.5 and $+3.0^{\circ} \mathrm{C}$ : (a) using two cultivars of SaeChal and HeenChal. Horizontal bars represent \pm 1 standard deviation ( $\mathrm{n}=9$ for the four variety treatments in Fig. $4 a$ and $n=12$ for the three temperature regimes in Fig. 4b).

The capability of the CERES-barley model to reproduce current and future barley productivities was verified using experimental data for two barley varieties (SaeChal and HeenChal) grown under three temperature regimes $\left(\mathrm{AT},+1.5^{\circ} \mathrm{C}\right.$, and $+3.0^{\circ} \mathrm{C}$ ) in TGFC. Simulated grain yields had a statistically significant agreement with measured grain yields (Fig. 4b). Based on paired t-test, simulated mean grain yields $\left(4841 \mathrm{~kg} \mathrm{ha}^{-1}\right.$ in 2015 and $4366 \mathrm{~kg}$ $\mathrm{ha}^{-1}$ in 2016) were similar to measured mean grain yields (5233 $\mathrm{kg} \mathrm{ha}^{-1}$ in 2015, p $=0.268 ; 4806 \mathrm{~kg} \mathrm{ha}^{-1}$ in 2016, $\mathrm{p}=0.447)$. These simulated grain yields agreed with measured grain yields, with and NSME values of $979.2 \mathrm{~kg}$ $\mathrm{ha}^{-1}$ and -3.39 in 2015 and $718.8 \mathrm{~kg} \mathrm{ha}^{-1}$ and 0.33 in 2016, respectively. 
Table 2. Genetic coefficients of the four barley cultivars used in this study

\begin{tabular}{cccccc}
\hline Generic coefficient* & Unit & SaeChal & HeenChal & KeunAl & Dajin \\
\hline P1V & Day & 10 & 10 & 10 & 10 \\
P1D & $\%$ & 23 & 23 & 20 & 20 \\
P5 & ${ }^{\circ} \mathrm{C}$ day & 230 & 220 & 180 & 100 \\
G1 & no g & 22 & 22 & 22 \\
G2 & $\mathrm{mg}$ & 29 & 25 & 34 & 43 \\
G3 & $\mathrm{g}$ & 1.5 & 1.5 & 1.5 & 1.5 \\
PHINT & ${ }^{\circ} \mathrm{C}$ day & 93 & 93 & 90 & 93 \\
\hline
\end{tabular}

*P1V - optimum temperature required for vernalization, P1D - photoperiod response $(\%$ reduction in the rate per $10 \mathrm{~h}$ drop in the photoperiod), P5 - grain filling (excluding lag) phase duration, G1 - kernel number per unit canopy weight at anthesis, G2 - standard kernel size under optimum conditions, G3 - standard, non-stressed mature tiller weight, PHINT - interval between successive leaf tip appearances.

Grain yields of barley were projected to increase as the temperature was raised up to $3.0^{\circ} \mathrm{C}$ for Dajin, $2.0^{\circ} \mathrm{C}$ for SaeChal and $\mathrm{KeunAl}$, and $1.0^{\circ} \mathrm{C}$ for HeenChal above the current conditions. They would then decrease (Fig. 5a). Grain yields of barley increased as $\mathrm{CO}_{2}$ concentration increased up to $500 \mathrm{ppm}$. Subsequently, a plateau was maintained, similar to the pattern for all barley cultivars (Fig. 5b).When elevation effects of temperature and $\mathrm{CO}_{2}$ were combined, simulated grain yields of barley increased as the combination of temperature and $\mathrm{CO}_{2}$ concentration increased up to $1.5^{\circ} \mathrm{C}$ and $600 \mathrm{ppm}$ (Fig. 5c). Grain yields of barley reached a plateau after an elevated regime of the temperature of $1.5^{\circ} \mathrm{C}$ and $\mathrm{CO}_{2}$ concentration of $600 \mathrm{ppm}$, with a similar pattern for all barley cultivars. Dajin was more responsive to temperature and $\mathrm{CO}_{2}$ variations than the other cultivars.

The GCSM system formulated to simulate the potential impact of climate change on barley projected increases of grain yields for all four barley varieties for the whole nation in the future, i.e., years 2030, 2050, 2070, and 2100 under both RCP4.5 and RCP8.5 scenarios (Fig. 6). Grain yields of all barley cultivars showed large spatial variations within geographical regions of the whole country, showing higher yields in southern coastal areas and lower yields in inner mountainous regions. Mean grain yields of all barley cultivars in the future under the RCP8.5 scenario would vary from region to region in 2030 and 2050. They would increase rapidly in 2070 and 2100 for most of the administrative areas and the whole country, except Jeju (Fig. 7). In Jeju, mean grain yields are likely to decrease rapidly in 2070 and 2100. Mean grain yields of barley under RCP4.5 scenario were projected to increase mostly in a small amount in the future compared to those at baseline, with a slow increasing pattern until 2070 and a gradually decreasing trend in 2100 for most regions except Jeju, where mean grain yields are likely to drop in 2070 and 2100. Mean grain yields under the RCP8.5 scenario
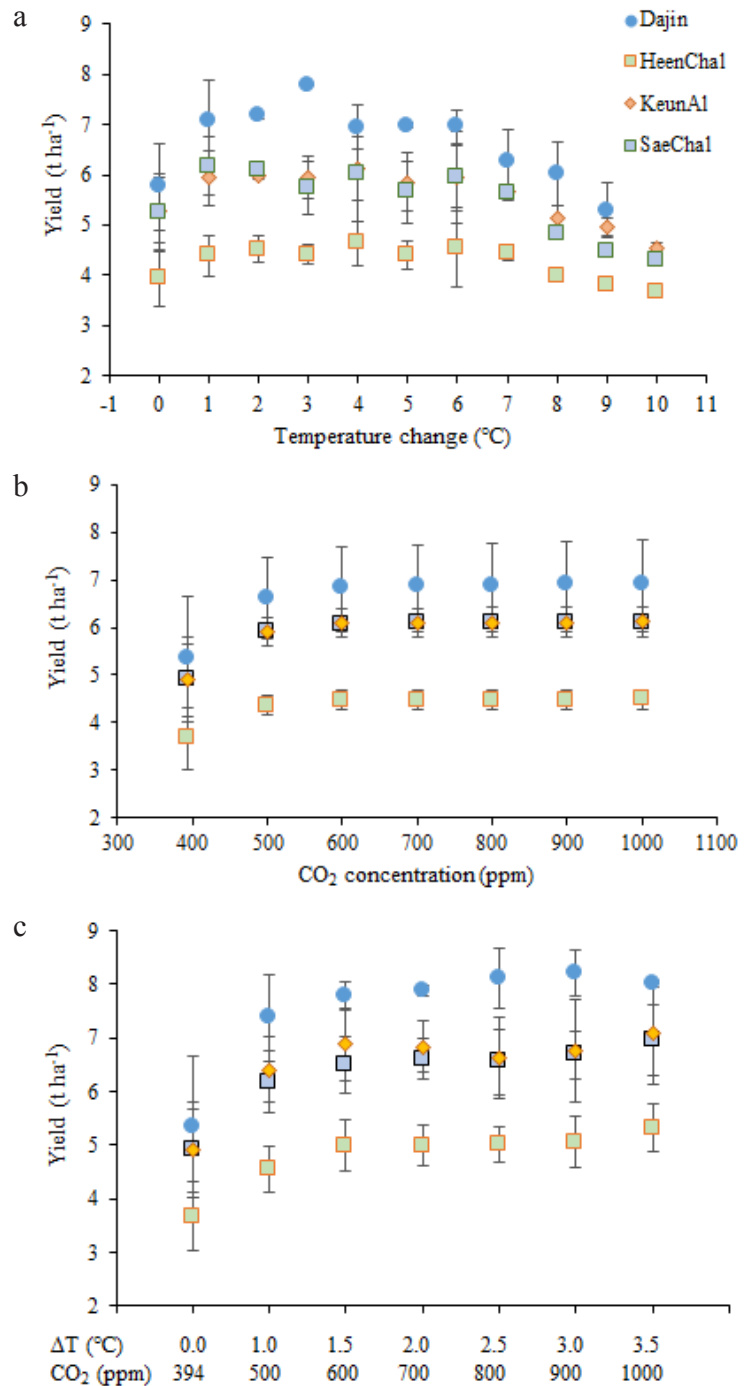

Fig. 5. Responses of grain yields of barley to temperature changes, $\Delta \mathrm{T}$ (a), $\mathrm{CO}_{2}$ concentrations (b), and combinations of $\Delta \mathrm{T}$ and $\mathrm{CO}_{2}$ (c). Vertical bars represent \pm 1 standard deviation $(\mathrm{n}=3)$. 

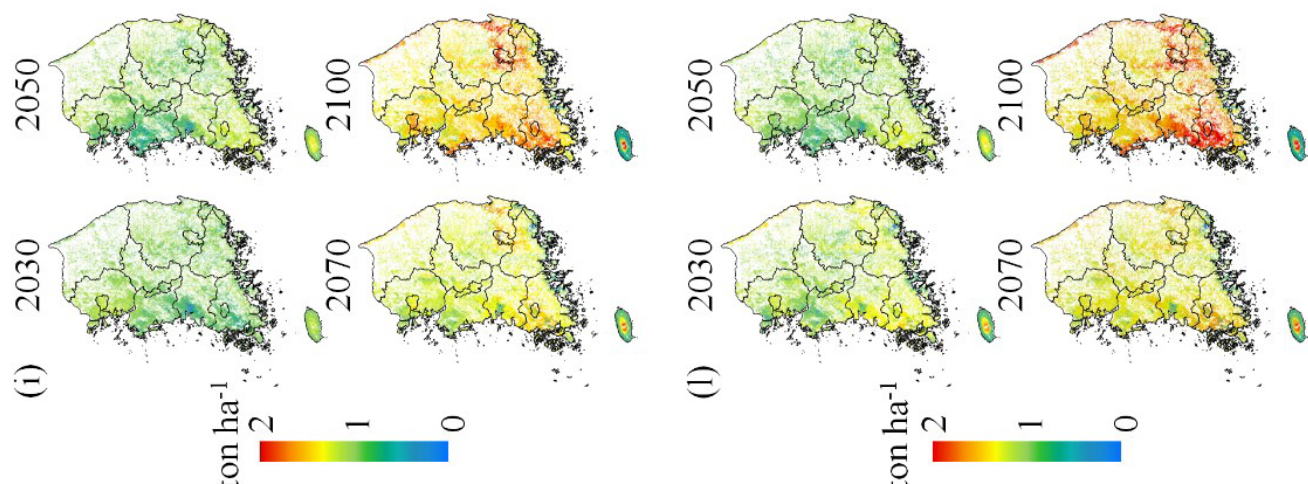

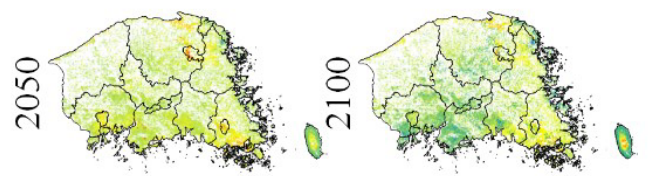
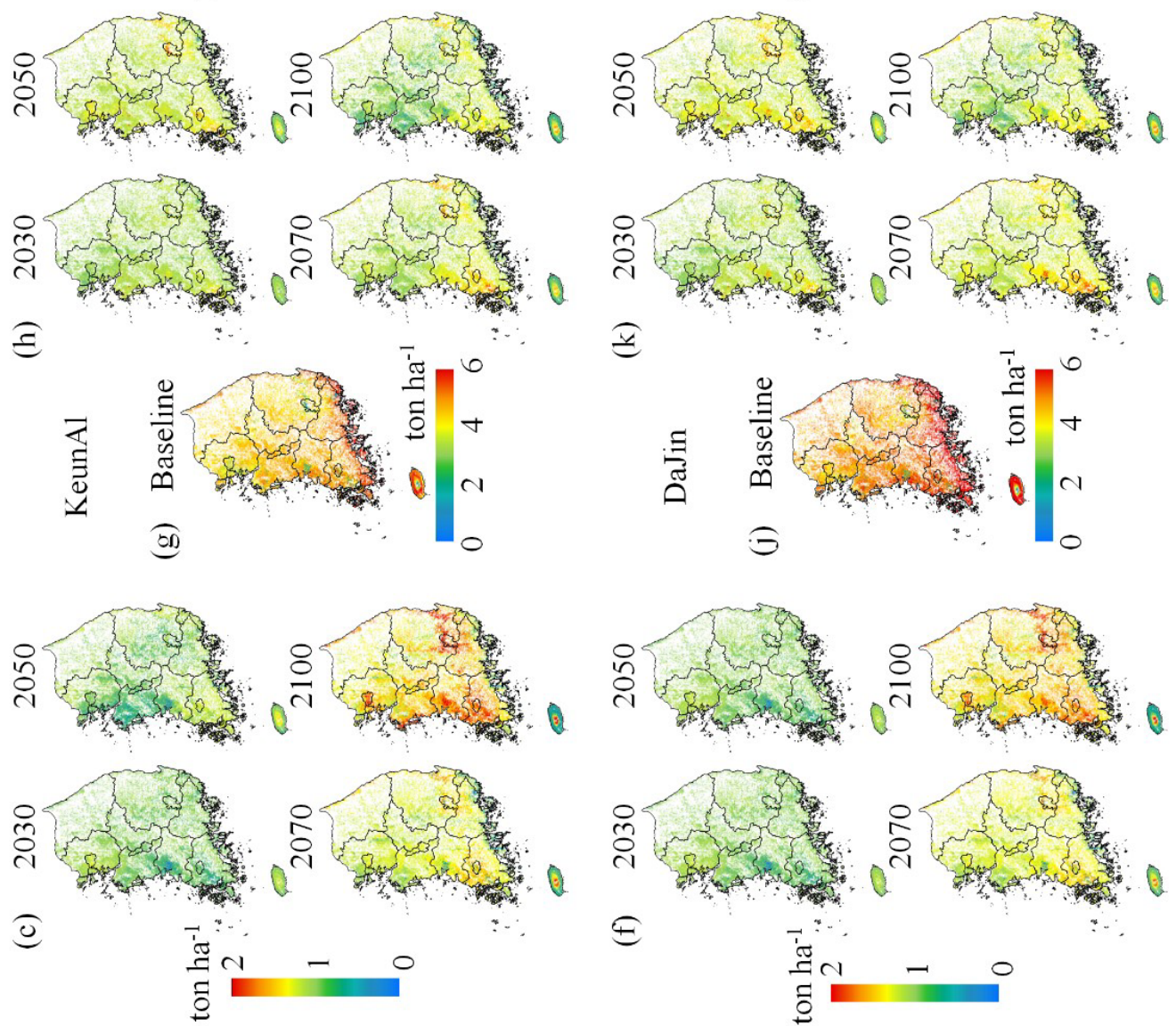

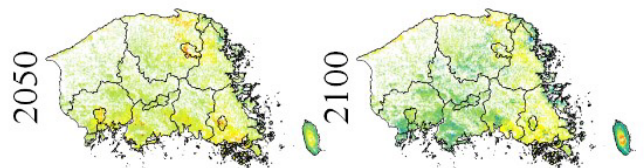
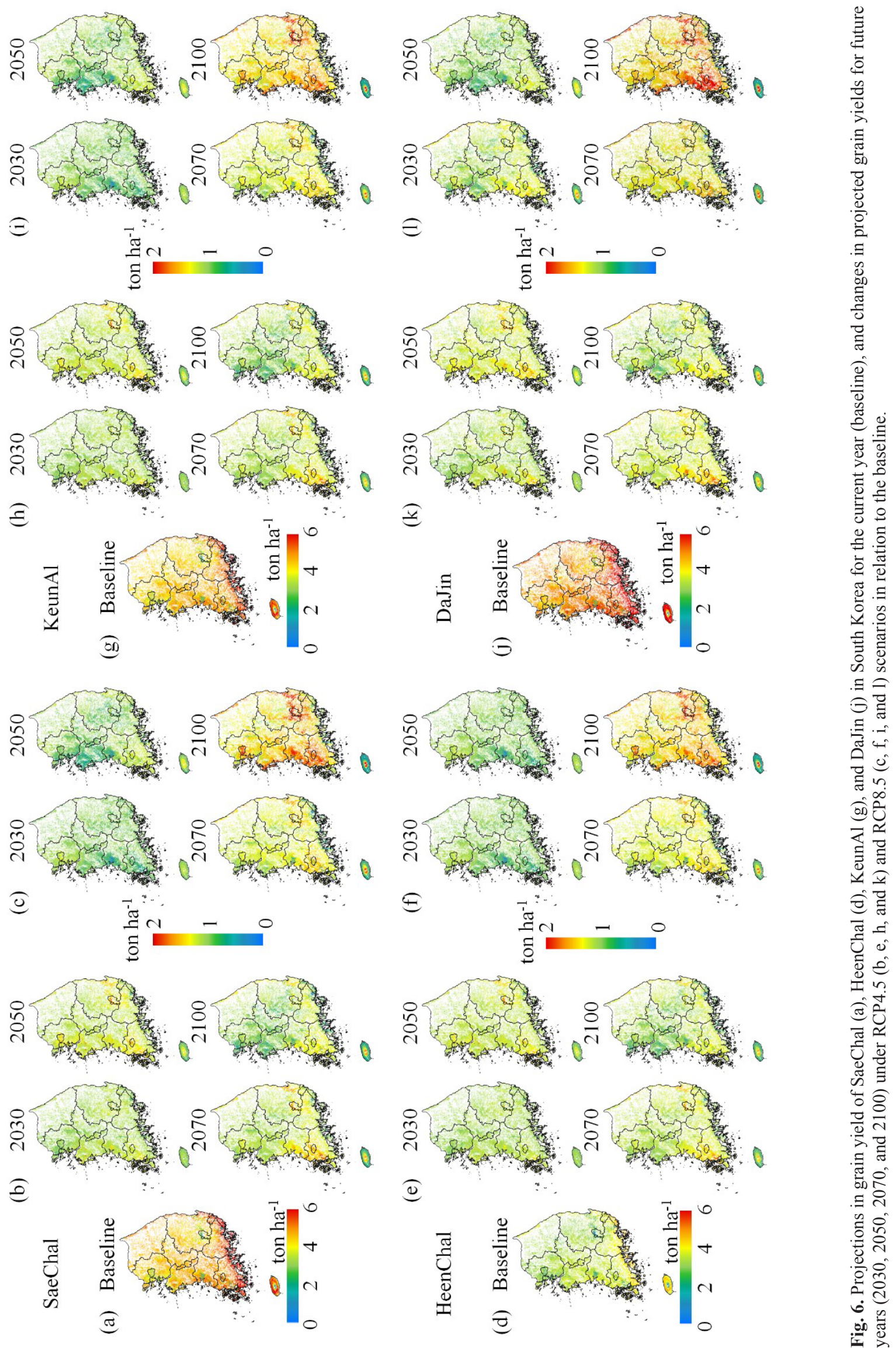

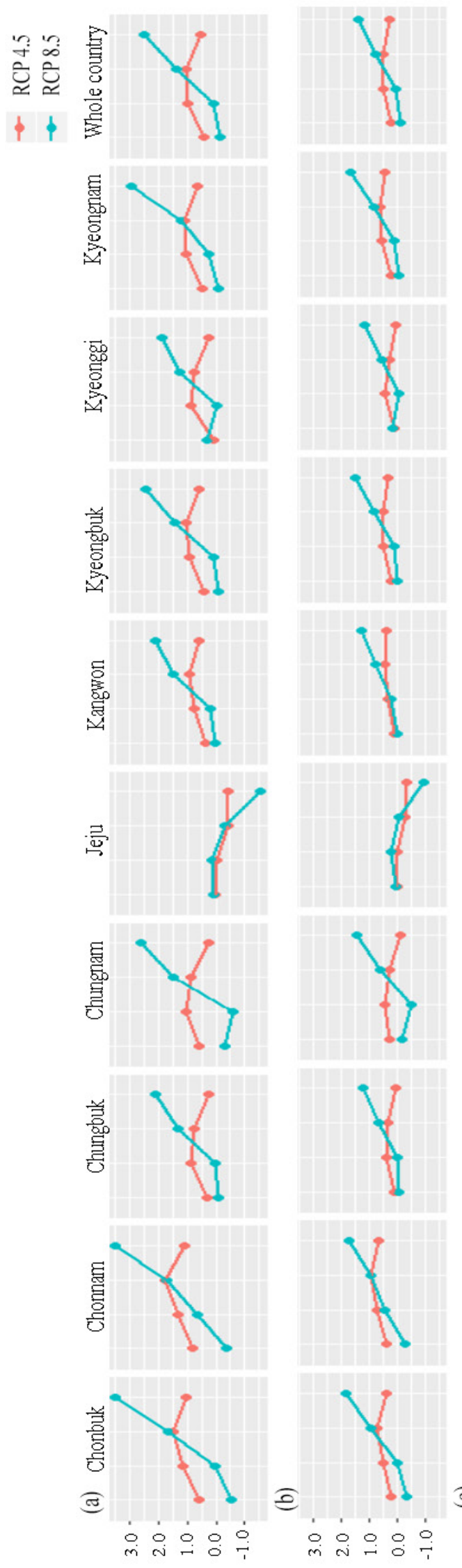

(
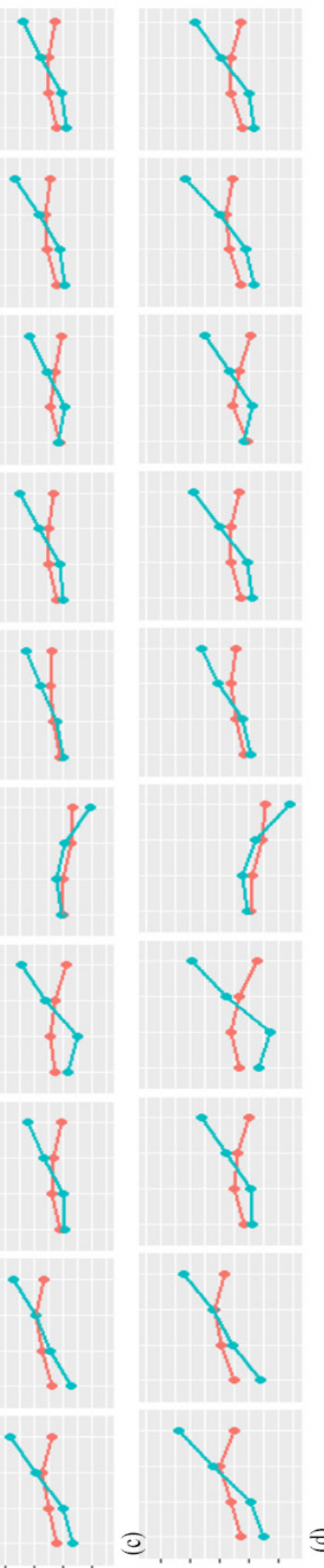

$\circ \circ \circ \circ 0$

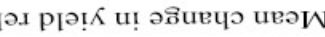
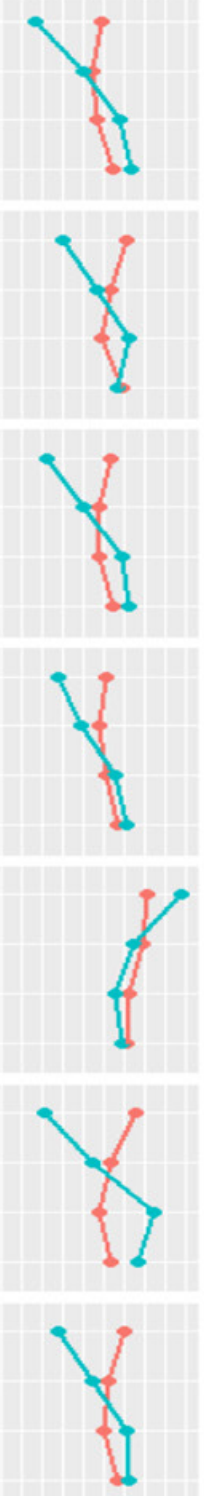

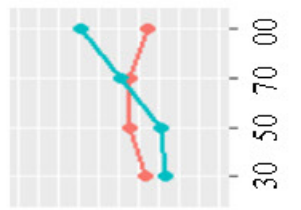

$1-8$

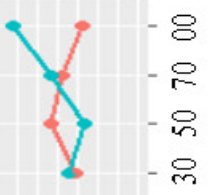

$1-8$
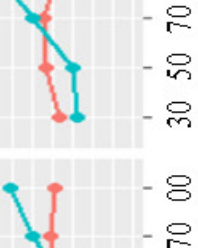

응
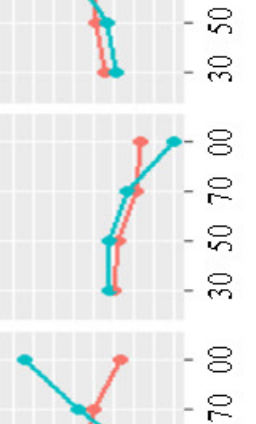

웅

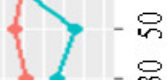

$-\stackrel{\circ}{-\infty}$

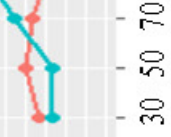

$\circ$

$-8$

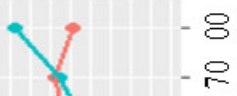

$-8$

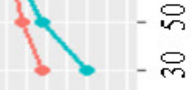

¿

$\stackrel{0}{3}$

(5)

용

ஓ

เั

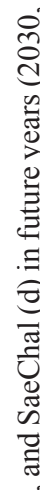

व.

อิ 
Table 3. Percent changes of barley yields in future years $(2030,2050,2070$, and 2100) from the baseline under the representative concentration pathway (RCP) 8.5 scenario and the RCP4.5 scenario in South Korea (SK) and nine administrative provinces

\begin{tabular}{|c|c|c|c|c|c|c|c|c|}
\hline \multirow{2}{*}{ Region } & \multicolumn{4}{|c|}{ RCP 8.5} & \multicolumn{4}{|c|}{$\mathrm{RCP} 4.5$} \\
\hline & 2030 & 2050 & 2070 & 2100 & 2030 & 2050 & 2070 & 2100 \\
\hline Chonbuk & -13.6 & -3.5 & 25.0 & 53.8 & 5.0 & 13.7 & 21.2 & 21.1 \\
\hline Chonnam & -7.9 & 11.7 & 26.4 & 49.6 & 11.2 & 20.7 & 26.5 & 17.7 \\
\hline Chungbuk & -2.1 & -0.8 & 20.6 & 38.2 & 4.4 & 13.2 & 10.1 & 1.2 \\
\hline Chungnam & -6.4 & -17.1 & 21.1 & 46.9 & 9.4 & 15.9 & 10.9 & -2.4 \\
\hline Gangwon & -0.6 & 5.0 & 25.2 & 38.1 & 4.8 & 9.8 & 13.5 & 11.1 \\
\hline Gyeonggi & 5.5 & -2.3 & 19.2 & 37.8 & 1.6 & 15.8 & 10.7 & 19.7 \\
\hline Jeju & 1.3 & 3.4 & -4.4 & -26.6 & -0.1 & -1.5 & -8.2 & -10.1 \\
\hline Kyeongbuk & -1.9 & 1.8 & 24.8 & 45.3 & 7.1 & 15.7 & 16.6 & 8.9 \\
\hline Kyeongnam & 1.7 & 7.0 & 26.8 & 55.1 & 6.9 & 16.1 & 18.2 & 12.3 \\
\hline SK & -2.7 & 0.5 & 22.3 & 42.9 & 6.7 & 11.9 & 16.0 & 7.5 \\
\hline
\end{tabular}

were projected to decline by $-2.7 \%$ by 2030 compared to those at baseline and to increase rapidly from $+22.3 \%$ in 2050 to $+42.9 \%$ in 2100 , while those under the RCP 4.5 scenario were projected to increase by $+16.0 \%$ by 2050 and by $+7.5 \%$ by 2100 (Table 3 ). For nine administrative regions (Chonbuk, Chonnam, Chungbuk, Chungnam, Jeju, Kangwon, Kyunggi, Kyungbuk, and Kyungnam), mean grain yields were projected to increase with trends similar to those of the whole nation except for Jeju, although some variations exist due to different meteorological and environmental conditions. In the case of Jeju, mean grain yields were projected to decrease gradually in the future (from $+3.4 \%$ in 2050 to $-26.6 \%$ in 2100 under RCP 8.5 and from $-1.5 \%$ in 2050 to $-10.1 \%$ in 2100 under RCP4.5) (Table 3).

The entire country could be classified into six geographical units (types) based on k-means clustering using eight variables (i.e., changes from the baseline to 2030 , from 2030 to 2050, from 2050 to 2070, and from 2070 to 2100 under both the RCP4.5 and RCP8.5 scenarios). The distribution of each of these six landscape types is shown in Fig. 8. Contour plots (Fig. 8a, 8g, 8m, and 8s) show the distribution of geographical unit Type 1 in the country. Type 1 is scattered over South Korea. Type 1 exists even in regions in which other units dominate. On Jeju Island, it is concentrated in mountainous areas in the central part. Type 2 is focused on the southwestern part of South Korea, particularly in Chonnam Province. There are substructures even in Chonnam. Chonnam has a mixture of Types 1 and 2. Coastal Jeju region is a unique geographical unit of Type 3. Both Types 4 and 6 stretch from northwest to south- east. However, Type 6 shows a broader distribution than Type 4 . Chungnam mainly has Type 6 . Type 5 is distribued in coastal areas in the south excluding Jeju Island. Proportions of these six geographical units in each administrative district for four barley cultivars are shown in bar charts (Fig. 9). The impact of climate change on different geographical units (Type) is shown in Fig. 10. Mean grain yields of all barley cultivars in the future under RCP8.5 and RCP4.5 scenarios compared to those at baseline are likely to vary for different geographical Types. Mean grain yields under RCP 8.5 were projected to increase gradually in Type 1, but rapidly in Type 2, as year processed. However, those under RCP4.5 are likely to maintain small increases in both Types. In Type 3, grain yields under both RCP8.5 and RCP 4.5 scenarios were projected to decline gradually with time. In Type 4, grain yields under RCP8.5 scenario are likely to remain constant or decrease in 2030 and 2050 but increase in 2070 and 2100, while those under RCP4.5 scenario are likely to increase only in 2050 . In Type 5 , grain yields under RCP8.5 were projected to decline in 2030 , 2050, and 2070 but rise sharply in 2100, while those under RCP4.5 are likely to maintain constant in 2030, 2050, and 2070 but drop dramatically in 2100 . In Type 6 , grain yields under RCP8.5 scenario possibly will decrease in small amounts in 2030 and 2050 but increase rapidly in 2070 and 2100 , while those under RCP4.5 may potentially maintain constant in 2030, grow in low numbers in 2050 and 2070, and decrease in 2010. 


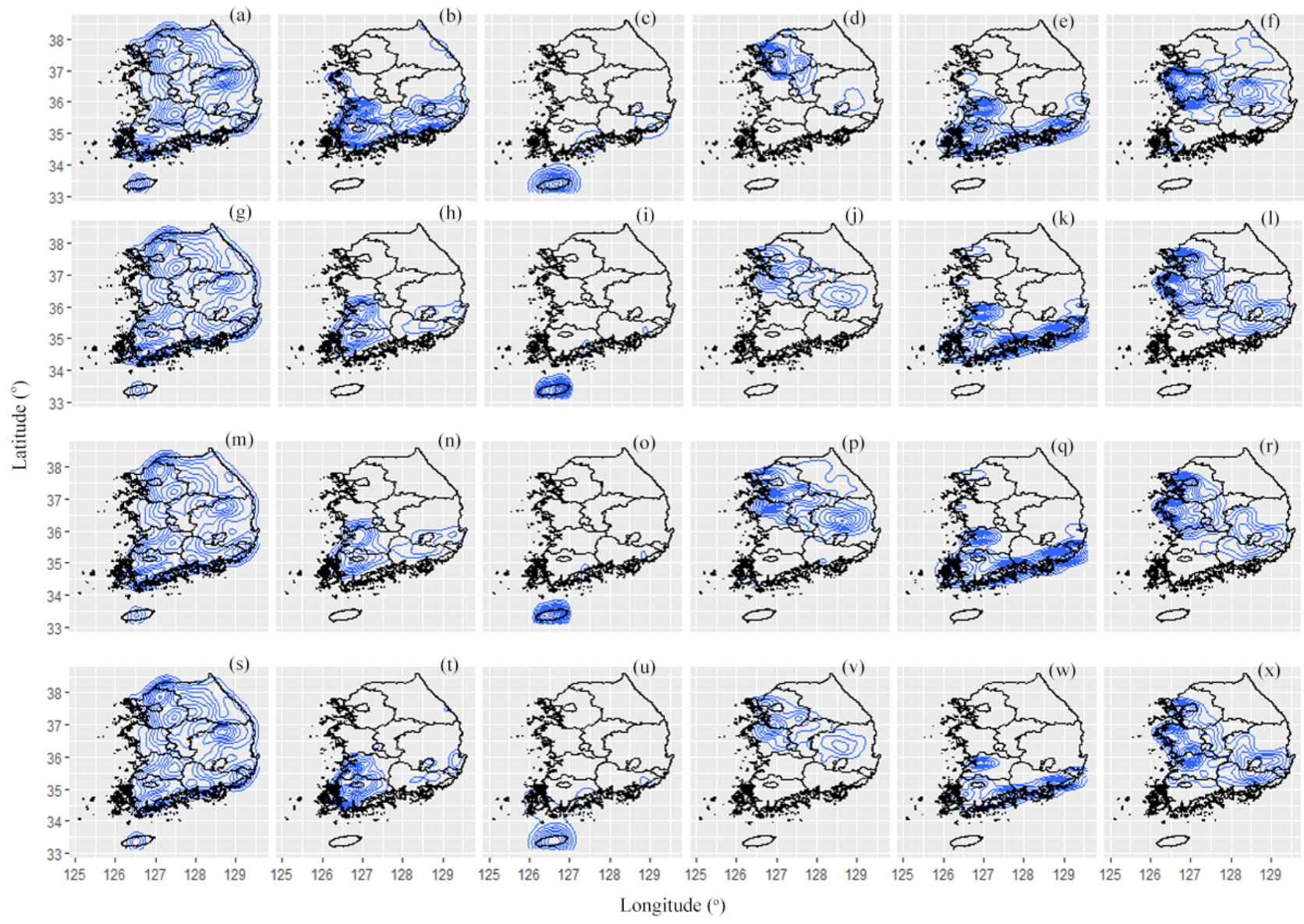

Fig. 8. Grouping of simulated grain yields of four barley varieties of DaJin (a-f), HeenChal (g-1), KeunAl (m-r), and SaeChal (s-x) in South Korea according to eight different variables (from now to 2030, from 2030 to 2050, from 2050 to 2070, and from 2070 to 2100 under both RCP4.5 and RCP8.5 scenarios) using k-means cluster examination: Type =1 (a, g, m, and s), Type = 2 (b, h, n, and t), Type $=3(\mathrm{c}, \mathrm{j}, \mathrm{o}$, and $\mathrm{u})$, Type $=4(\mathrm{~d}, \mathrm{j}, \mathrm{p}$, and v), Type $=5(\mathrm{e}, \mathrm{k}, \mathrm{q}$, and $\mathrm{w})$, and Type $=6(\mathrm{f}, \mathrm{l}, \mathrm{r}$, and $\mathrm{x})$.

\section{DISCUSSION}

An evaluation system for estimating the impact of climate change on barley yield and capable of projecting productivities for large regions containing a significant amount of data was developed. Expected yields of four barley cultivars for the entire nation of South Korea indicated gradual increases as year progressed under the RCP4.5 scenario. They presented rapid increases under the RCP8.5 scenario (refer to Table 3). It appears that barley is constrained by low temperatures in South Korea so that potentially elevated temperatures allow an increase in growth and yield. Meanwhile, more discrepancies were observed in yield responses for diverse topographical regions. Results of the current study suggest that the proposed GCSM system using the CERES-barley model in DSSAT v4.6 could be a useful tool to simulate crop productivity under climate change scenarios to investigate the potential impact of regional climate change on crop yields and remedial measures for future agricultural regimes.
While considerable efforts have been made to enumerate global crop productions, especially considering the changing climate (Lobell and Field 2007; Rosenzweig et al., 2014), it might be unmanageable at present to measure the collective impact of climate change on global agricultural productivity (Gornall et al., 2010). Difficulties mainly stem from complications as regards an adequate classification of cultivated lands, uncertainties of climate projection models, and genetic, environmental, and regional variabilities in crop production. The global distribution of arable areas is likely to change continuously not only due to current drivers of socio-economic development and environmental changes but also due to potential impacts of climate change (Ramankutty et al., 2002). It is also likely that the variability in regional and global crop productivity will significantly change (Lobell et al., 2011; Olesen et al., 2011; Thornton et al., 2009). Therefore, a more typical and advanced crop modelling scheme that can reproduce spatiotemporal crop productivity with a fine grid scale is necessary to deliver local changes of crop production. There 


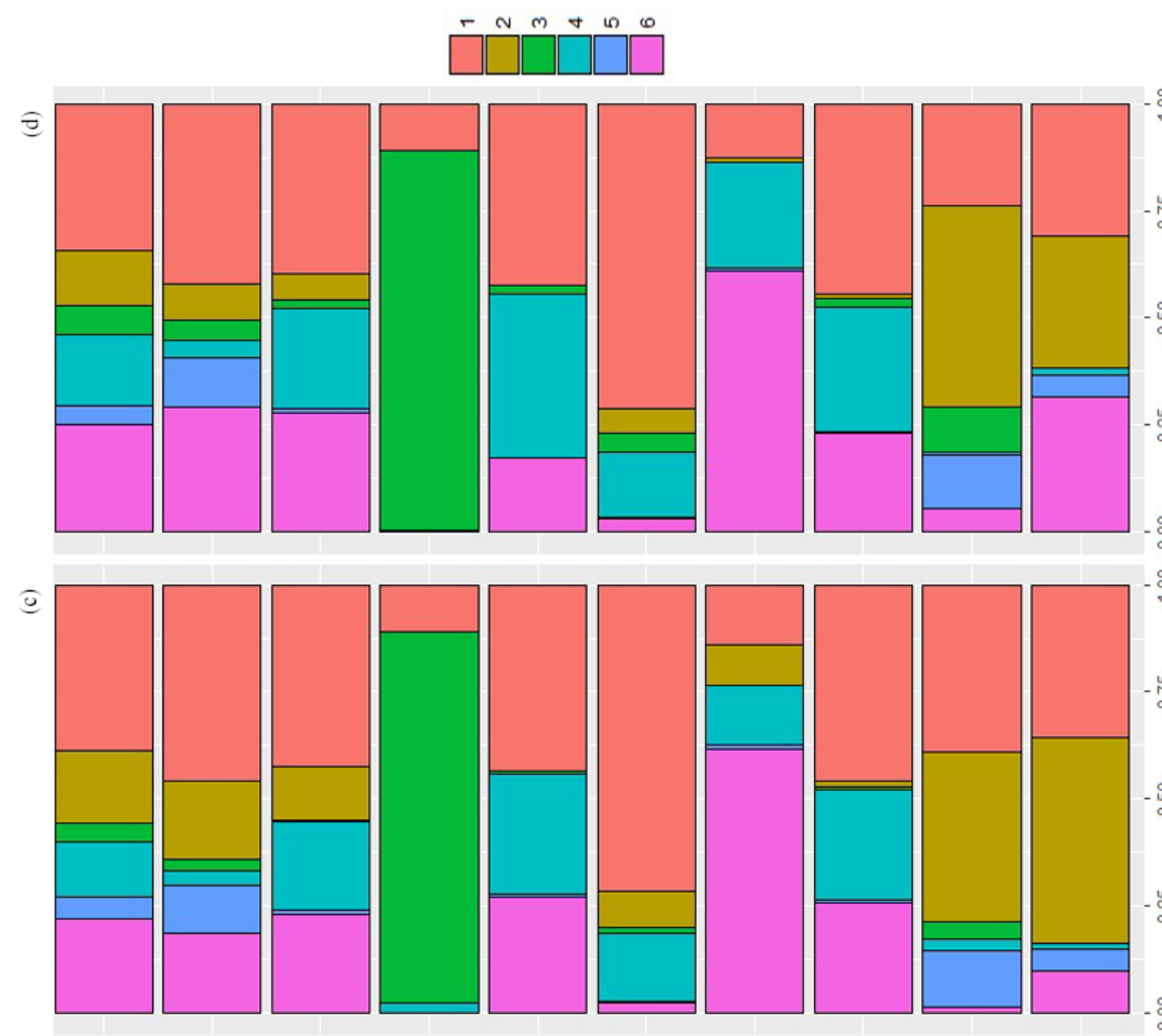

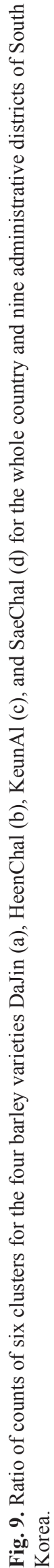




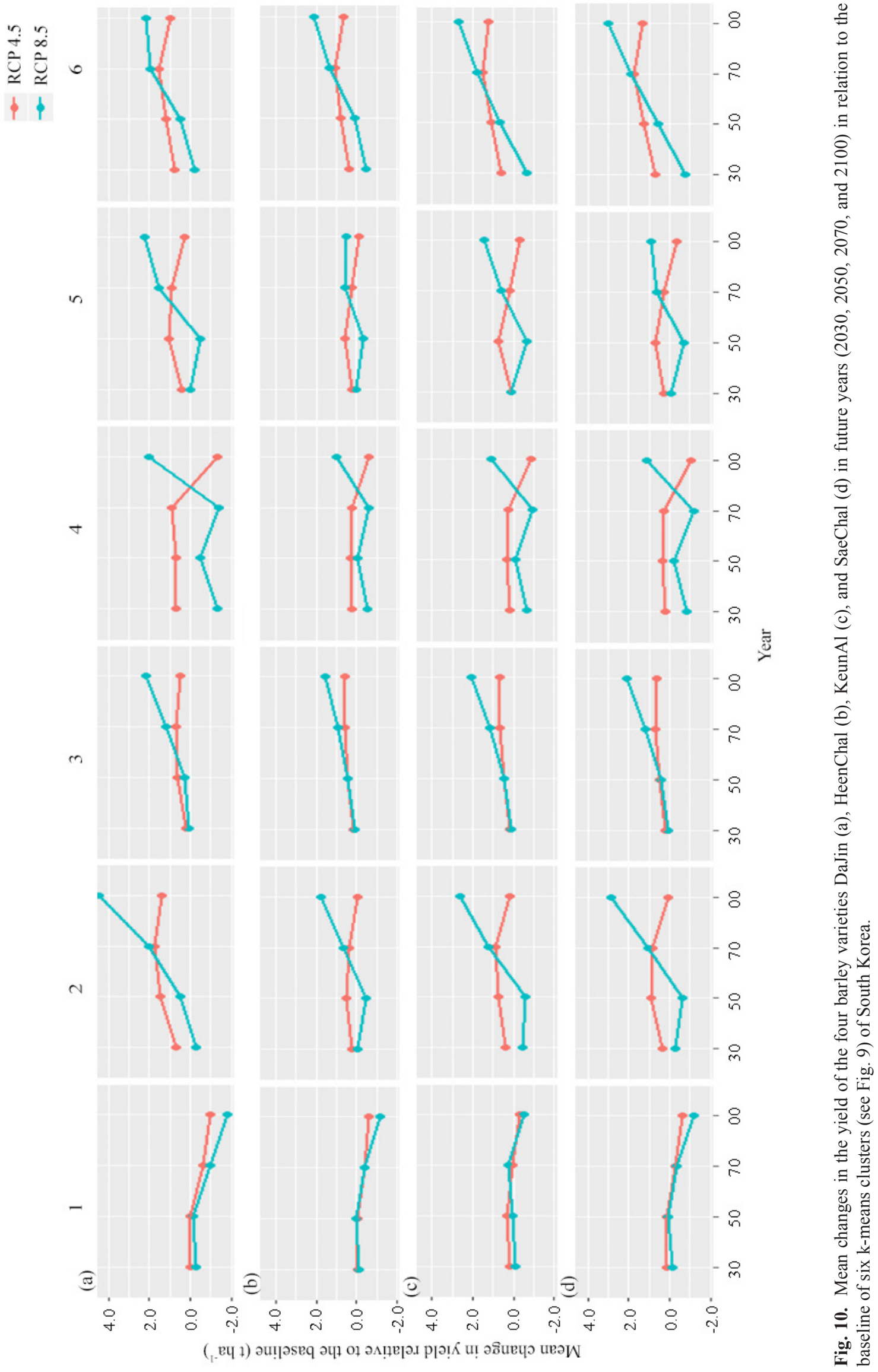


have been some efforts to simulate geospatial variations to determine impacts of climate change on staple crops, e.g., paddy rice in Southeast Asia (Li et al., 2017; Chun et al., 2016) and maize and bean in East Africa (Thornton et al., 2009). To the best of our information, the current research is the first one that simulates the effect of climate change on barley with a fine grid $(3 \mathrm{~km})$-based regional yield projection by categorising regional productivity using k-means clustering.

Results of ANOVA for simulated barley yields categorised using four factors (RCP scenario, year, region, and cultivars) indicated that year and area were the most important factors while varieties and climate scenario were far less critical (Table 4). This analysis coincided with interpretations based on the diagram shown in Fig. 7. The scenario-year interaction had the most substantial influence on the total variation of crop yield, followed by year and region. Cultivar and cultivar-related interaction terms were far less critical. Therefore, RCP scenario, year, area, and their interactions are important factors explaining crop yield variations. This fact is coherent with results shown in Fig. 7 where crop yield trajectory patterns do not seem to differ from cultivar to cultivar significantly.

The impact of climate change on crop production varies depending on diverse climate types and soil textures. South Korea comprises six climate types: Cfa, Cwa, Dfa, Dfb, Dwa, and Dwb based on the Koeppen-Geiger grouping system (Kottek et al., 2006). Allowing for eight different dominant soil textures spread out in croplands of South Korea based on the USDA classification, we can assume a total of $6 \times 8$ groupings of climate-soil types. Clustering allowed us to reduce local characteristics of the entire country from 48 to six classes.

Decision-making procedures in agricultural policy issues can be either country-wide or area-specific. The dissemination of Type 1 might be useful for us to evaluate the prospect of introducing country-wide climate change policies (Fig. 8). The spread of other types might be beneficial for the purpose of determining area-specific strategies. However, further efforts should be followed to obtain detailed classification information on the distribution of

Table 4. Analysis of variance (ANOVA) for simulated barley yields categorized using four factors: climate scenario (RCP4.5 and RCP8.5), year (2030, 2050, 2070, and 2100), region (Chonbuk, Chonnam, Chungbuk, Chungnam, Kangwon, Kyunggi, Kyungbuk, Kyungnam, and Juju), and cultivar (Dajin, HeenChal, KeunAl, and SaeChal)

\begin{tabular}{lcccc}
\hline Factor & Percentage & DF & SS & MS \\
\hline Residuals & 44.08 & 28512 & 13245277403 & 464551 \\
Scenario (S) & 0.58 & 1 & 173886850 & 1738866850 \\
Year $(\mathrm{Y})$ & 11.58 & 3 & 3479041728 & 1159680576 \\
Region (R) & 10.21 & 8 & 3068141596 & 383517700 \\
Cultivar $(\mathrm{C})$ & 1.90 & 3 & 569808813 & 189936271 \\
$\mathrm{~S} * \mathrm{Y}$ & 14.10 & 3 & 4235876624 & 1411958875 \\
$\mathrm{~S} * \mathrm{R}$ & 0.36 & 8 & 106734930 & 13341866 \\
$\mathrm{~S} * \mathrm{C}$ & 0.01 & 24 & 19448100 & 649367 \\
$\mathrm{Y} * \mathrm{R}$ & 8.28 & 9 & 2489422439 & 103725935 \\
$\mathrm{Y} * \mathrm{C}$ & 0.45 & 24 & 134685501 & 14965056 \\
$\mathrm{R} * \mathrm{C}$ & 0.96 & 24 & 288189472 & 12007895 \\
$\mathrm{~S} * \mathrm{Y} * \mathrm{R}$ & 5.91 & 9 & 1775864518 & 73994355 \\
$\mathrm{~S} * \mathrm{Y} * \mathrm{C}$ & 0.60 & 24 & 181601392 & 20177932 \\
$\mathrm{~S} * \mathrm{R} * \mathrm{C}$ & 0.11 & 33642758 & 1401782 \\
$\mathrm{Y} * \mathrm{R} * \mathrm{C}$ & 0.54 & 162637949 & 2258860 \\
$\mathrm{~S} * \mathrm{Y} * \mathrm{R} * \mathrm{C}$ & 0.34 & 103558740 & 1438316 \\
\hline
\end{tabular}


each geographical Type and relationships of the data with other factors such as climate variables and geographic characteristics.

Limitations of the current study include climate projection models used and the baseline applied. An ensemble approach using multiple climate projection models would better represent the variability of projected climate changes on simulation of the impact of climate change on crops (Ko et al., 2012; Thornton et al., 2009). For higher probability to represent current and future climate variabilities, a 20 to 30-year baseline is considered (White et al., 2011). We used a 12-year baseline due to the limited availability of grid-based high-resolution regional climate data.

\section{CONCLUSIONS}

1. It was demonstrated that the CERES-barley model in DSSAT v4.6 was capable of reproducing current field conditions and projecting crop productivity under different climate change scenarios. Also, a geospatial crop simulation modelling using the model was developed and effectively applied to reproduce geospatial variation in barley yield in South Korea.

2. Regional characteristics of South Korea could be classified into six categories according to a cluster analysis.

3. Results obtained provided a preview of the likely impact of local climate change on barley grain yields and would allow to determine counteractive actions for future agricultural activities.

4. Although the developed geospatial crop simulation modelling system needs additional elaboration to meet the requirements of a particular tool for scientists and stakeholders, we believe that this system could be efficiently used to reproduce geospatial dissimilarities of climate change impact on crops and search for probable clarifications to the impending food uncertainty problem.

Conflict of interest: The Authors do not declare conflict of interest.

\section{ACKNOWLEDGEMENT}

The authors wish to thank Professor Joong-Bae Ahn at Pusan National University for providing the climate data for this study.

\section{REFERENCES}

Ahn J., Hur J., and Shim K., 2010. A simulation of the agroclimate index over the Korean Peninsula using dynamical downscaling with a numerical weather prediction model. Kor. J. Agric. Forest Meteorol., 12, 1-10.

Ahuja L.R., Rojas K.W., Hanson J.D., Shafer M.J. and Ma L., (Eds), 2000. Root Zone Water Quality Model. Modeling management effects on water quality and crop production. Water Resources Publications, LLC, CO, USA.

Allen L.H., Boote K.J., Jones J.W., Valle R.R., Acock B., Rogers H.H., and Dahlman R.C., 1987. Response of vege- tation to rising carbon dioxide: photosynthesis, biomass, and seed yield of soybean. Global Biochem. Cycles, 1, $1-14$.

Bunce J.A., 2000. Responses of stomatal conductance to light, humidity and temperature in winter wheat and barley grown at three concentrations of carbon dioxide in the field. Global Change Biol., 6, 371-382.

Chloupeka O., Hrstkovaa P., and Schweigert P., 2004. Yield and its stability, crop diversity, adaptability and response to climate change, weather and fertilisation over 75 years in the Czech Republic in comparison to some European countries. Field Crops Res., 85, 167-190.

Chun J., Li S., Wang Q., Lee W., Lee E., Horstmann N., Park H., Veasna T., Vanndy L., Pros K., and Vang S., 2016. Assessing rice productivity and adaptation strategies for Southeast Asia under climate change through multi-scale crop modeling. Agric. Syst., 143, 14-21.

FAO, 2017. Crops/Regions/World List/Production Quantity for Barley, 2014 (pick list). Food and Agriculture Organization Corporate Statistical Database (FAOSTAT).

Godwin D.C., Ritchie J.T., Singh U., and Hunt L.A., 1989. A User's Guide to CERES-wheat - v2.10. Int. Fert. Develop. Center, Muscle Shoals, 89 pp.

Gornall J., Betts R., Burke E., Clark R., Camp J., Willett K., and Wilshire A., 2010. Implications of climate change for agricultural productivity in the early twenty-first century. Phil. Trans. Royal Soc., B, 365, 2973-2989.

Hijmans R.J., Guiking-Lens I.M., and van Diepen C.A., 1994. WOFOST 6.0: User's guide for the WOFOST 6.0 crop growth simulation model. Wageningen, Nederland.

Hong S., Zhang Y., Hyun B., Sonn Y., Kim Y., Jung S., Park C., Song K., Jang B., Choe E., Lee Y., Ha S., Kim M., Lee J., Jung G., Ko B., and Kim G., 2009. An introduction of Korean soil information system. Kor. J. Soil Sci. Fert., 42, 21-28.

IPCC, 2013. Climate change 2013: the physical science basis. Contribution of Working Group I to the Fifth Assessment Report of the Intergovernmental Panel on Climate Change (Eds T.F. Stocker D. Qin G.-K. Plattner M.M.B. Tignor S.K. Allen J. Boschung A. Nauels Y. Xia V. Bex, and P.M. Midgley). Cambridge University Press, New York, NY, USA.

Jamieson P.D., Berntsen J., Ewert F., Kimball B.A., Olesen J.E., Pinter Jr., P.J., Porter J.R., and Semenov M.A., 2000. Modeling $\mathrm{CO}_{2}$ effects on wheat with varying nitrogen supplies. Agric. Ecosys. Environ., 82, 27-37.

Jones J.W., Hoogenboom G., Porter C.H., Boote K.J., Batchelor W.D., Hunt L.A., Wilkens P.W., Singh U., Gijsman A.J., and Ritchie J.T., 2003. The DSSAT cropping system model. Europ. J. Agron., 18, 235-265.

Kim H., Lim S., Kwak J., Lee D., Lee S., Ro H., and Choi W., 2011. Dry matter and nitrogen accumulation and partitioning in rice (Oryza sativa L.) exposed to experimental warming with elevated $\mathrm{CO}_{2}$. Plant Soil, 32, 59-71.

Kirschbaum M.U.F., 2000. Forest growth and species distribution in a changing climate. Tree Physiol., 20, 309-322.

Ko J., Ahuja L.R., Saseendran S.A., Green T.R., Ma L., Nielsen D.C., and Walthall C.L., 2012. Climate change impacts on dryland cropping systems in the Central Great Plants, USA. Climatic Change, 111, 445-472. 
Kottek M., Grieser J., Beck C., Rudolf B., and Rubel R., 2006. World map of the Koppen-Geiger climate classification updated. Meteorologische Zeitschrift, 15, 259-263.

Li S., Wang Q., and Chun J., 2017. Impact assessment of climate change on rice productivity in the Indochinese Peninsula using a regional-scale crop model. Int. J. Climatol., 34, 1147-1160.

Lobell D.B. and Field C.B., 2007. Global scale climate-crop yield relationships and the impacts of recent warming. Environ. Res. Lett., 2, 1-7.

Lobell D.B., Schlenker W., and Costa-Roberts J., 2011. Climate trends and global crop production since 1980. Science, 333, 616-620.

Long S.P., Ainsworth E.A., Leakey A.D.B., Nosberger J., and Ort D.R., 2006. Food for thought: Lower-than-expected crop yield stimulation with rising $\mathrm{CO}_{2}$ concentrations. Science, 312, 1918-1921.

McMaster G.S., 1993. Another Wheat (Triticum spp.) Model? Progress and applications in crop modeling. Rivista di Agronomia, 27, 264-272.

Nash J.E. and Sutcliffe J.V., 1970. River flow forecasting through conceptual models: Part I. A discussion of principles. J. Hydrol., 10, 282-290.

Olesen J.E., Trnka M., Kersebaum, K.C., Skjelvåg A.O., Seguin B., Peltonen-Sainio P., Rossi F., Kozyra J., and Micale F., 2011. Impacts and adaptation of European crop production systems to climate change. Europ. J. Agron., 34, 96-112.

Otter-Nacke S., Rirchie J.T., Godwin D.C., and Singh U., 1991. A User's Guide to CERES Barley- V2.10, International Fertilizer Development Center Simulation Manual, IFDCSM-3, 87 pp.

Peart R.M., Jones R.B., Curry K., Boote K.J., and Allen L.H., 1989. Impacts of climate change on crop yield in the Southern U.S.A. In: The potential effects of global climate change on the United States, Report to Congress (Eds J.B. Smith, D.A. Tirpak), U.S. Environmental Protection Agency, EPA-230-05-89-050, Washing D.C., Appendix C.

Ramankutty N., Foley J.A., Norman J., and McSweeney K., 2002. The global distribution of cultivable lands: current patterns and sensitivity to possible climate change. Global Ecol. Biogeog., 11, 377-392.
Reyenga P.J., Howden S.M., Meinke H., and McKeon G.M., 1999. Modeling global climate change impacts on wheat cropping in south-east Queensland, Australia. Aust. Enviro. Model Software, 14, 297-306.

Rosenzweig C., Elliott J., Deryngd D., Ruane A.C., Müllere C., Arneth A., Boote K.J., Folberth C., Glotter M., Khabarov N., Neumann K., Piontek F., Pugh T.A.M., Schmid E., Stehfest E., Yang H., and Jones J.W., 2014. Assessing agricultural risks of climate change in the $21 \mathrm{st}$ century in a global gridded crop model intercomparison. PNAS, 111, 3268-3273.

Tao F., Rötter R.P., Palosuo T., Díaz-Ambrona C.G.H., Mínguez M.I., Semenov M.A., Kersebaum K.C., Nendel C., Cammarano D., Hoffmann H., Ewert F., Dambreville A., Martre P., Rodríguez L., Ruiz-Ramos M., Gaiser T., Höhn J.G., Salo T., Ferrise R., Bindi M., and Schulman A.H., 2017. Designing future barley ideotypes using a crop model ensemble. Europ. J. Agron., 82, 144-162.

Thornton P.K., Jones P.G., Alagarswamy G., and Andersen J., 2009. Spatial variation of crop yield response to climate change in East Africa. Global Environ. Change, 19, 54-65.

Trnka M., Dubrovský M., and Žalud Z., 2004. Climate change impacts and adaptation strategies in spring barley production in the Czech Republic. Climatic Change, 64, 227-255.

Tubiello F.N., Donatelli M., Rosenzweig C., and Stockle C.O., 2000. Effects of climate change and elevated $\mathrm{CO}_{2}$ on cropping systems: model predictions at two Italian locations. Europ. J. Agron., 13, 179-189.

White J.W., Hoogenboom G., Kimball B.A., and Wall G.W., 2011. Methodologies for simulating impacts of climate change on crop production. Field Crops Res., 124, 357-368.

Williams J.R., Jones C.A., Kiniry J.R., and Spanel D.A., 1989. The EPIC crop growth model. Trans. ASAE, 32, 497-511.

Yun S., Kang B., Lim S., Choi W., Ko J., Yoon S., Ro H., and Kim H., 2012. Further understanding $\mathrm{CH}_{4}$ emissions from a flooded rice field exposed to experimental warming with elevated $\left[\mathrm{CO}_{2}\right]$. Agric. For. Meteorol., 154, 75-83.

Zawadzki J., Cieszewski C.J., Zasada M., and Lowe R.C., 2005. Applying geostatistics for investigations of forest ecosystems using remote sensing imagery. Silva Fenica., 39(4): 599-617. 